\title{
Assessment of general movement among infants not at risk of developmental delay
}

\section{Roksana Malak}

Department and Clinic of Rheumatology and Rehabilitation, Poznan University of Medical Sciences, Poland

(D) https://orcid.org/0000-0003-0521-5249

Corresponding author: rmalak@ump.edu.pl

\section{Joanna Borek}

Department and Clinic of Rheumatology and Rehabilitation, Poznan University of Medical Sciences, Poland

(D) https://orcid.org/0000-0003-3959-7214

\section{Dorota Sikorska}

Department and Clinic of Rheumatology and Rehabilitation, Poznan University of Medical Sciences, Poland

(D) https://orcid.org/0000-0001-7326-6916

\section{Przemysław Keczmer}

Department and Clinic of Rheumatology and Rehabilitation, Poznan University of Medical Sciences, Poland

(iD https://orcid.org/0000-0001-7403-5300

\section{Włodzimierz Samborski}

Department and Clinic of Rheumatology and Rehabilitation, Poznan University of Medical Sciences, Poland

(D) https://orcid.org/0000-0002-0338-894X
DOI: https://doi.org/10.20883/medical.393

Keywords: general movements, infants, motor development

\section{Published: 2020-06-30}

How to cite: Malak R, Borek J, Sikorska D, Keczmer P, Samborski W. Assessment of general movement among infants not at risk of developmental delay. JMS [Internet]. 2020 Mar 31;89(2):e393. doi:10.20883/medical.393

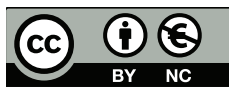

(c) 2020 by the author(s). This is an open access article distributed under the terms and conditions of the Creative Commons Attribution (CC BY-NC) licencse. Published by Poznan University of Medical Sciences

\begin{abstract}
Introduction. The functional assessment of general movements (GMs) is a common test for the developing nervous system. The high predictive validity of abnormal GMs for cerebral palsy has been documented among preterm infants.

Aim. The present study examined whether term infants without any documented risk factors for neurodevelopment delay may benefit from an assessment of GMs.

Methods. One hundred and four infants ranging in age from 1-4 months were evaluated using Prechtl's method, of which, thirty-eight were younger than two months of age and the remaining sixty-eight were older than two months of age (with available detailed neonatal characteristics). The following movements were considered among younger infants, writhing, poor repertoire and cramped synchronised, whereas fidgety, cramped synchronised, poor repertoire, chaotic and abnormal GMs were evaluated in older infants. Infants were classified as 'normal' or 'abnormal' groups based on their presenting GMs. We determined postural positional preference, following Kaplan recommendations, with features categorised as either 'present' or 'absent', as well as activity level and general muscle tone ('normal' or 'abnormal').

Results. Cramped synchronised GMs were observed in seven (18.4\%) younger infants and in eleven (16.7\%) older infants. There was no difference in the clinical characteristics of children with normal vs. abnormal GMs. Abnormal muscle tone was associated with a higher OR $(p=0.0039)$ of presenting with abnormal GMs (4.6063; 95\% Cl: 1.6303-13.0149). Although the infants studied were not at risk for developmental disorders, almost one-fifth required follow-up neurological consultation.

Conclusions. An assessment of GMs should be considered as a universal screening tool among healthy infants without risk factor(s) for developmental deficits.
\end{abstract}




\section{Introduction}

The observation of an infant's movement is an essential part of a child's examination. General Movement (GM) assessment is a reliable tool for identifying infants at risk of neuromotor deficits [1]. GMs are spontaneous motor behaviours with rotations around the limb axes and fluent changes in the direction of movement, generated by central pattern generators (CPGs) located in the brainstem and can be classified as normal and abnormal GMs. Normal GMs consist of "writhing movements", which are present in early foetal life until the end of the second month, and "fidgety movements", which are observable from 3 to 5 months after term. "Writhing" and "fidgety" movements are tiny movements of the neck, trunk, and limbs in all directions and of variable acceleration. Abnormal GMs can include: (a) poor repertoire GMs, which are characterised by the monotonous sequence of movement components; (b) cramped synchronised GMs, which lack the usual smoothness and may be described as rigid limb and trunk contraction; (c) chaotic GMs, which are an abrupt and tremulous movement with large amplitude and high speed; and (d) abnormal fidgety movements with exaggerated amplitude, speed and even jerkiness [1]. If fidgety movements are absent at 3-5 months, the infant may develop severe neurological deficits such as cerebral palsy [2]. At $98 \%$ sensitivity, the assessment of GMs is not only a useful clinical instrument for early identification of cerebral palsy but also a good predictor of later cognition and behaviour, even at school age [3]. Normal fidgety GMs have been associated with a high intelligence quotient (IQ) as early as 7-10 years of age $[1,4]$.

The examination of an infant using GMs is safe and non-invasive. During a GM assessment, the child is in the supine position without elicited or intrusive handling. The results of the assessment allow for the application of appropriate therapy to improve motor development as early as possible, which may prevent some motor abnormalities [5].

GM assessment is frequently used as a functional assessment tool for the young nervous system. Indeed, the authors of the Acts of the World Health Organisation recommend performing a functional assessment of children [6-8]. The authors reported that the results of the functional evaluation of children and adolescents correlated with ratings of the children's behaviour, social relations, and school abilities [6-8].

\section{Aim}

The study aimed to (1) test whether infants without perinatal risk factors for neurodevelopmental delay should also undergo a GM assessment, and (2) characterise the types of GMs that are present.

\section{Material and Methods}

\section{Study group}

The study group consisted of 104 infants (57 male, 47 female), $1-4$ months of age (mean \pm SD: $1.8 \pm 0.8$ months). All infants from the study group had an appointment in the medical centre because their parents were interested in testing whether their child's motor development was normal. The programme, entitled "Healthy Baby", was free to parents and designed by the Department of Health and Social Affairs. GMs were evaluated in infants by clinicians from the Poznań University of Medical Science. All parents gave written informed consent for their child to complete the assessment. The study was approved by the Bioethical Committee of Poznań University of Medical Sciences, Poland (339/15).

The following inclusion criteria were applied to infants:

1. Patient aged less than 4 months.

2. Patient born in hospitals in the city of Poznań. The exclusion criteria included:

1. Infants with immediately life-threatening conditions.

2. Active inflammation, infections, or lethal diseases.

\section{Material and Methods}

GMs were assessed in infants using the noninvasive method designed by Prechtl. First, the infants were divided into two groups based on age: (1) infants younger than two months of age ( $\mathrm{n}=38$ infants), (2) infants older than two months of age ( $n=68$ infants). In the younger group, we 
tested for writhing, poor repertoire, and cramped synchronised GMs. In the older group, we tested for fidgety, cramped synchronised, poor repertoire, abnormal and chaotic GMs. Infants were further divided into presenting with 'normal' or 'abnormal' GMs.

Postural positional preference was also determined according to recommendations by Sandra L. Kaplan $[9,10]$. General muscle tone and activity level were assessed according to Prechtl's method and referring to the Neonatal Behavioural Assessment Scale $[1,11]$. The activity level was also evaluated as a component of GM observation [1]. In all assessments, features were categorised as 'present' or 'absent' for postural positional preference, and as 'normal' or 'abnormal' for activity level and general muscle tone. The parents were also interviewed to assess the neonatal characteristics of their child.

\section{Statistical analysis}

The values are expressed as median [interquartile range $-I Q R]$ if not stated otherwise. The non-parametric Mann-Whitney $U$ test was used to test for group differences in continuous variables. Two-tailed Fisher's exact test was applied to test for group differences in categorical variables. Data were analysed using STATISTICA 8.1 (StatSoft). All statistical significance levels were set at $p \leq 0.05$.

\section{Results}

Infants in this study were born between the $36^{\text {th }}$ and $41^{\text {st }}$ week of gestation, with birth weight ranging from 2,500 to $4,580 \mathrm{~g}$. Umbilical cord blood artery $\mathrm{pH}$ ranged from 7.1 to 7.42 . Ninetyone of the 104 infants received 10 points in the fifth minute of the Apgar score, and the lowest observed value was 8 . The mode of delivery for most patients was natural ( $n=52$ patients), 40 patients were born by caesarean section, 9 vacuum extraction, and 3 had a forceps delivery. Jaundice was diagnosed in 64 infants and 14 patients required treatment with phototherapy.

Thirty-one out of $38(81.6 \%)$ infants in the younger group ( $<2$ months of age) presented with "writhing" GMs and cramped synchronised GMs were observed in seven (18.4\%) infants. None of the infants in the younger group showed poor repertoire GMs. Cramped synchronised GMs were observed in 11 out of the 66 (16.7\%) infants in the older age group. No infants in the older group presented with poor repertoire, abnormal or chaotic GMs. To summarise, $17.3 \%$ of infants across both groups (younger, older) showed cramped synchronised GMs. Although these infants were not at risk of developmental disorders, almost one-fifth of infants required a follow-up visit to a neurologist.

Infants presenting with normal vs. abnormal GMs did not differ in clinical characteristics, either in the younger (Table 1) or older group (Table 2). The difference remained non-significant even after combining both groups and considering the entire sample $(\mathrm{N}=104)$.

The distribution of postural preference and general muscle tone did not differ among the younger (Table 3) or older infants (Table 4). In the younger group, abnormal general muscle tone was more frequent $(p=0.025)$ in infants who presented with abnormal GMs compared to infants presenting with normal GMs. This association did not reach significance in the older group ( $p$ $=0.089$ ). Consideration of both groups together showed a significant difference $(p=0.0046)$ such that abnormal muscle tone was present in $57.9 \%$ (i.e., 11 out of 19) of infants with abnormal GMs vs. $23 \%$ (i.e., 20 out of 87 ) of infants with normal GMs. Abnormal muscle tone was associated with a higher $\mathrm{OR}(p=0.0039)$ of presenting with

Table 1. Clinical characteristics of younger infants ( $<2$ months of age) presenting with normal and abnormal GMs

\begin{tabular}{lccc} 
& $\begin{array}{c}\text { Normal GMs } \\
(\mathbf{n}=\mathbf{3 1})\end{array}$ & $\begin{array}{c}\text { Abnormal GMs } \\
(\mathbf{n = 7})\end{array}$ & p value \\
\hline Apgar score & $10(10-10)$ & $10(10-10)$ & 0.684 \\
\hline pH & $7.32(7.29-7.36)$ & $7.34(7.30-7.38)$ & 0.414 \\
\hline Birth weight $(\mathrm{g})$ & $3,560(3100-3980)$ & $3,160(3010-3950)$ & 0.498 \\
\hline Week of gestation & $39(38-40)$ & $39(38-41)$ & 0.643 \\
\hline
\end{tabular}

Data presented as median (IQR) 
Table 2. Clinical characteristics of older infants (>2 months of age) presenting with normal and abnormal GMs

\begin{tabular}{lccc} 
& $\begin{array}{c}\text { Normal GMs } \\
(\mathbf{n}=\mathbf{5 5})\end{array}$ & $\begin{array}{c}\text { Abnormal GMs }(\mathbf{n}= \\
\mathbf{1 1})\end{array}$ & $\boldsymbol{p}$ value \\
\hline Apgar & $10(10-10)$ & $10(10-10)$ & 0.445 \\
\hline pH & $7.32(7.26-7.38)$ & $7.31(7.22-7.39)$ & 0.890 \\
\hline Birth weight $(\mathrm{g})$ & $3,570(3160-3840)$ & $3,320(3230-3720)$ & 0.353 \\
\hline Week of gestation & $39(39-40)$ & $39(36-40)$ & 0.332 \\
\hline
\end{tabular}

Data presented as median (IQR)

Table 3. Associations between functional parameters and GMs in younger ( $<2$ months of age) infants

\begin{tabular}{|c|c|c|c|c|}
\hline & & $\begin{array}{l}\text { Normal GMs } \\
\quad(n=31)\end{array}$ & $\begin{array}{l}\text { Abnormal GMs } \\
(\mathbf{n}=7)\end{array}$ & $p$ value \\
\hline \multirow{2}{*}{ Postural preference } & Absent & 18 & 3 & \multirow{2}{*}{0.678} \\
\hline & Present & 13 & 4 & \\
\hline \multirow{2}{*}{ Activity level } & Normal & 28 & 5 & \multirow{2}{*}{0.223} \\
\hline & Abnormal & 3 & 2 & \\
\hline \multirow{2}{*}{ General muscle tone } & Normal & 27 & 3 & \multirow{2}{*}{0.025} \\
\hline & Abnormal & 4 & 4 & \\
\hline
\end{tabular}

Table 4. Associations between functional parameters and GMs in older (>2 months of age) infants

\begin{tabular}{|c|c|c|c|c|}
\hline & & $\begin{array}{c}\text { Normal GMs } \\
(n=55)\end{array}$ & $\begin{array}{c}\text { Abnormal GMs } \\
(n=11)\end{array}$ & $p$-value \\
\hline \multirow{2}{*}{ Postural preference } & Absent & 17 & 5 & \multirow{2}{*}{0.485} \\
\hline & Present & 38 & 6 & \\
\hline \multirow{2}{*}{ Activity level } & Normal & 55 & 11 & \multirow{2}{*}{-} \\
\hline & Abnormal & 0 & 0 & \\
\hline \multirow{2}{*}{ General muscle tone } & Normal & 39 & 5 & \multirow{2}{*}{0.159} \\
\hline & Abnormal & 16 & 6 & \\
\hline
\end{tabular}

abnormal GMs $(4.6063 ; 95 \% \mathrm{Cl}$ [confidence interval]: 1.6303-13.0149). There were just five infants in the younger group who presented with abnormal activity levels. Two of the five infants with abnormal activity levels also showed abnormal GMs. No infants in the older group presented with abnormal activity levels (Table 4).

To summarise, although infants were not at risk of developmental disorders, $18 \%$ of infants across both groups required a follow-up visit to a neurologist.

\section{Discussion}

The present study demonstrated that almost one in five infants presented abnormal GMs. We assessed healthy full-term infants without risk factors for developmental delays. Although the predictive validity of abnormal GMs for cerebral palsy is better in infants born preterm, we demonstrated that GMs should also be considered in infants born at term $[2,12]$. GMs in healthy infants is a useful clinical instrument for the early identification of not only cerebral palsy, but also a good predictor of later cognition, attention, and behavioural problems at school age $[3,13]$. The observation of movement should be a routine assessment within the first few months of life in all children $[13,15,16]$, which is in line with World Health Organisation recommendations (b761, b7610, International Classification of Functioning, Disability and Health: Children and Youth Version) [7]. Early identification of disordered movement may be a marker of early brain impairment and/or dysfunction. Disordered GMs may have more predictive utility in preterm infants compared to term infants because brain lesions are more heterogeneous in full-term infants. Importantly, GM assessments have a sensitivity and specificity of $98 \%$ and $95 \%$, respectively. Furthermore, compared to magnetic resonance imaging, brain ultrasound, and traditional neurological examinations, GM assessments are quick, non-invasive, and cost-effective [14]. 
The present study indicated that infants, particularly in the younger group and presenting with abnormal GMs, frequently showed abnormal muscle tone. Physiological hypertonia of term infants in the first two months of life should not always be a cause for concern for clinicians because hypertonia may be an expression of increased motoneuronal excitability which subsequently decreases around 3 months of age [17]. Nonetheless, abnormal muscle tone may be a symptom of hypoxic-ischaemic encephalopathy with additional characteristics of perinatal features such as Apgar $<5$ in the $5^{\text {th }}$ minute and $\mathrm{pH} \leq 7$ [18]. Importantly, infants in the present study did not have such risk factors. Our results suggest that general muscle tone may be an important feature that should be assessed in all infants $[3,19,20]$ to evaluate motor development $[21,22]$. We and others also recommend examining muscle tone not only with the "pull to sit" manoeuvre but also in several positions (e.g., supine, horizontal, vertical, and prone) [21]. Abnormal muscle tone may also be correlated with autism spectrum disorder [23].

We demonstrated that, even in a group of norisk infants, a subset may require a follow-up examination by a neurologist. The application of a GM assessment should allow physicians or therapists to determine whether an infant needs additional examination or therapy with good predictability [3].

Limitations of the study include a relatively small group of healthy infants and a limited number of physiological variables studied. Most infants included in the present study were eutrophic, born at term, and with proper birth weight. Moreover, we assessed infants who lacked significant developmental risk factors, such as intraventricular haemorrhage, hypoxia, acidosis, Apgar score $<7$, extremely low birth weight, or extremely early week of gestation. We also did not evaluate individual infant developmental trajectories.

Strengths of this study should also be noted. In contrast to previous studies, the present study assessed GMs among a group of healthy infants. Parents who were interested in whether their child showed appropriate motor development also confirmed that their child's development appeared normal. Nonetheless, the assessment of GMs may help to identify infants who should visit specialists, such as a neurologist.

\section{Conclusion}

In conclusion, even in a group of infants who were not at risk for cerebral palsy, a subset of infants required follow-up consultation, thus, GMs should be assessed in all infants. Early assessment provides the opportunity to help infants as early as possible, which has positive effects on long-term development.

\section{Acknowledgements}

This project was a part of the "Healthy Baby" study designed by the Department of Health and Social Affairs and Health Centre.

\section{Conflict of interest statement}

The authors declare no conflict of interest.

\section{Funding sources}

This research did not receive any specific grant from funding agencies in the public, commercial, or not-forprofit sectors. No clinicians were provided with compensation for completing the assessments described in this manuscript.

\section{References}

1. Nakajima Y, Einspieler C, Marschik PB, Bos AF, Prechtl HF. Does a detailed assessment of poor repertoire general movements help to identify those infants who will develop normally?. Early Human Development. 2006 Jan;82(1):53-59. https://doi.org/10.1016/j. earlhumdev.2005.07.010

2. Einspieler C, Prechtl HFR. Prechtl's assessment of general movements: A diagnostic tool for the functional assessment of the young nervous system. Mental Retardation and Developmental Disabilities Research Reviews. 2005;11(1):61-67. https://doi. org/10.1002/mrdd.20051

3. Ferrari F, Cioni G, Einspieler C, Roversi MF, Bos AF, Paolicelli PB, Ranzi A, Prechtl HFR. Cramped Synchronized General Movements in Preterm Infants as an Early Marker for Cerebral Palsy. Archives of Pediatrics \& Adolescent Medicine. 2002 May 1;156(5):460. https://doi.org/10.1001/archpedi.156.5.460

4. Hadders-Algra M. General movements: a window for early identification of children at high risk for developmental disorders. The Journal of Pediatrics. 2004 Aug;145(2):S12-S18. https://doi.org/10.1016/j. jpeds.2004.05.017

5. Smith T, Groen AD, Wynn JW. Randomized Trial of Intensive Early Intervention for Children With Pervasive Developmental Disorder. American Journal on Mental Retardation. 2000;105(4):269. https://doi.org/10.1352/0895-8017(2000)105<0269:rtoiei>2.0.co;2

6. Stellwagen L, Hubbard E, Chambers C, Jones KL. Torticollis, facial asymmetry and plagiocephaly in normal newborns. Archives of Disease in Childhood. 2008 Apr 1;93(10):827-831. https://doi.org/10.1136/ adc. 2007.124123 
7. van Vlimmeren $L A$, van der Graaf $Y$, BoereBoonekamp MM, L'Hoir MP, Helders PJM, Engelbert RHH. Effect of Pediatric Physical Therapy on Deformational Plagiocephaly in Children With Positional Preference. Archives of Pediatrics \& Adolescent Medicine. 2008 Aug 1;162(8):712. https://doi.org/10.1001/ archpedi.162.8.712

8. Brazelton TB, Nugent JK. The Neonatal Behavioral Assessment Scale. London: Mac Keith Press; 2011.

9. Einspieler C, Bos AF, Libertus ME, Marschik PB. The General Movement Assessment Helps Us to Identify Preterm Infants at Risk for Cognitive Dysfunction. Frontiers in Psychology. 2016 Mar 22;7. https://doi. org/10.3389/fpsyg.2016.00406

10. Spittle A, Orton J, Anderson PJ, Boyd R, Doyle LW. Early developmental intervention programmes provided post hospital discharge to prevent motor and cognitive impairment in preterm infants. Cochrane Database of Systematic Reviews. 2015 Nov 24;. https://doi.org/10.1002/14651858.cd005495.pub4

11. Gajewska E, Sobieska M, Kaczmarek E, Suwalska A, Steinborn B. Achieving Motor Development Milestones at the Age of Three Months May Determine, but Does Not Guarantee, Proper Further Development. The Scientific World Journal. 2013;2013:1-11. https://doi.org/10.1155/2013/354218

12. Hodges $\mathrm{K}$, Wong MM. Psychometric characteristics of a multidimensional measure to assess impairment: The Child and Adolescent Functional Assessment Scale. Journal of Child and Family Studies. 1996 Dec;5(4):445-467. https://doi.org/10.1007/ bf02233865

13. International Classification of Functioning, Disability and Health (ICF). https://www.who.int/classifications/icf/en

14. Gower L, Jenkins D, Fraser JL, Ramakrishnan V, Coker-Bolt P. Early developmental assessment with a short screening test, the STEP, predicts one-year outcomes. Journal of Perinatology. 2018 Oct 9;39(2):184192. https://doi.org/10.1038/s41372-018-0234-4

15. Chugani HT, Phelps ME, Mazziotta JC. Positron emission tomography study of human brain functional development. Annals of Neurology. 1987 Oct;22(4):487-497. https://doi.org/10.1002/ ana. 410220408
16. International classification of functioning, disability and health: children and youth version: ICF-CY. https://apps.who.int/iris/handle/10665/43737

17. Fjørtoft T, Grunewaldt KH, Løhaugen GCC, Mørkved S, Skranes J, Evensen KAI. Assessment of motor behaviour in high-risk-infants at 3months predicts motor and cognitive outcomes in 10years old children. Early Human Development. 2013 Oct;89(10):787-793. https://doi.org/10.1016/j.earlhumdev.2013.06.007

18. Prechtl HF, Einspieler C, Cioni G, Bos AF, Ferrari F, Sontheimer D. An early marker for neurological deficits after perinatal brain lesions. The Lancet. 1997 May;349(9062):1361-1363. https://doi.org/10.1016/ s0140-6736(96)10182-3

19. Einspieler C, Marschik PB, Milioti S, Nakajima Y, Bos $A F$, Prechtl HF. Are abnormal fidgety movements an early marker for complex minor neurological dysfunction at puberty?. Early Human Development. 2007 Aug;83(8):521-525. https://doi.org/10.1016/j. earlhumdev.2006.10.001

20. Bruggink JL, Einspieler C, Butcher PR, Van Braeckel KN, Prechtl HF, Bos AF. The Quality of the Early Motor Repertoire in Preterm Infants Predicts Minor Neurologic Dysfunction at School Age. The Journal of Pediatrics. 2008 Jul;153(1):32-39.e1. https://doi. org/10.1016/j.jpeds.2007.12.047

21. Yuge $M$, Marschik PB, Nakajima $Y$, Yamori $Y$, Kanda T, Hirota H, Yoshida N, Einspieler C. Movements and postures of infants aged 3 to 5 months: To what extent is their optimality related to perinatal events and to the neurological outcome?. Early Human Development. 2011 Mar;87(3):231-237. https://doi. org/10.1016/j.earlhumdev.2010.12.046

22. Papazian O. Encefalopatía hipóxica-isquémica neonatal [Neonatal hypoxic-ischemic encephalopathy]. Medicina (B Aires). 2018;78(Suppl. 2):36-41. PMID 30199363

23. Razaz N, Cnattingius S, Persson M, Tedroff K, Lisonkova S, Joseph KS. One-minute and five-minute Apgar scores and child developmental health at 5 years of age: a population-based cohort study in British Columbia, Canada. BMJ Open. 2019 May;9(5):e027655. https://doi.org/10.1136/bmjopen2018-027655 